\title{
Agonist Occupancy Is Essential for Forward Trafficking of AMPA Receptors
}

\author{
Sarah K. Coleman, ${ }^{1}$ Tommi Möykkynen, ${ }^{3}$ Annukka Jouppila, ${ }^{1}$ Susanna Koskelainen, ${ }^{1}$ Claudio Rivera, ${ }^{2}$ Esa R Korpi, ${ }^{3}$ \\ and Kari Keinänen ${ }^{1}$ \\ ${ }^{1}$ Department of Biological and Environmental Sciences, Division of Biochemistry, and 2Institute of Biotechnology, Viikki Biocenter, University of Helsinki, \\ FI-00014 Helsinki, Finland, and ${ }^{3}$ Institute of Biomedicine, Division of Pharmacology, Biomedicum Helsinki, University of Helsinki, FI-00290 Helsinki, \\ Finland
}

Regulated trafficking of AMPA receptors to cell surface and to synapses is an important determinant of neuronal excitability. In the present study, we have addressed the role of agonist binding and desensitization in the early trafficking of glutamate receptor-D (GluR-D) AMPA receptors. Analysis of point-mutated GluR-D receptors, via electrophysiology and immunofluorescence, revealed that agonistbinding activity is essential for efficient delivery to cell surface in transfected cell lines and in neurons. Cotransfection with stargazin could fully rescue the surface expression of nonbinding mutant receptors in cell lines, indicating that stargazin is able to interact with and promote exit of AMPA receptors from endoplasmic reticulum (ER) independently of agonist binding. Secretion of separately expressed ligand-binding domain constructs showed a similar dependency of agonist binding to that observed with full-length GluR-D, supporting the idea that glutamate-induced closure of the binding site cleft is registered by ER quality control as a necessary priming step for transport competence. In contrast to agonist binding, the ability of the receptor to undergo desensitization had only a minor influence on trafficking. Our results are consistent with the hypothesis that AMPA receptors are synthesized as intrinsically unstable molecules, which require glutamate binding for structural stability and for transport-competence.

Key words: AMPA receptor; ER exit; GluR-D; GluR4; receptor transport; stargazin

\section{Introduction}

Maturation of newly synthesized ionotropic glutamate receptors (iGluR) in the rough endoplasmic reticulum is subject to exquisite quality control mechanisms to ensure that only properly folded and assembled receptors are capable of leaving the endoplasmic reticulum (ER) in an efficient manner (Vandenberghe and Bredt, 2004). Consistent with findings on well characterized model proteins, exit of iGluR from ER is likely to require a stably folded oligomeric structure and may further depend on blocking or shielding of specific sequence motifs which hinder export from ER (for review, see Ellgaard and Helenius, 2003; Sitia and Braakman, 2003). Arginine-based ER retention signals (Michelsen et al., 2005) have been identified in the NMDA receptor subunit NR1 (Standley et al., 2000; Scott et al., 2001; Xia et al., 2001), in the kainate receptor subunits KA2 (Ren et al., 2003a; NasuNishimura et al., 2006), and GluR5 splice variant 2b (Ren et al., 2003b). For AMPA receptors, which form both GluR-B (GluR2) subunit-containing heteromeric receptors and GluR-B-lacking homomeric and heteromeric receptors, no such canonical ER

Received Aug. 19, 2008; revised 0ct. 23, 2008; accepted Nov. 26, 2008.

This work was supported by Academy of Finland Grant 110900 (to K.K.). We thank Miika Palviainen, Olaya Llano Shetal Soni, and Anastasia Ludwig for neuronal cultures; Dr. Ingemar von Ossowski for purification of Fab antibodies; and Danielle Bansfield for general technical assistance.

Correspondence should be addressed to Kari Keinänen, Department of Biological and Environmental Sciences, Division of Biochemistry, University of Helsinki, FI-00014 Helsinki, Finland. E-mail: kari.keinanen@helsinki.fi. DOI:10.1523/JNEUROSCI.3953-08.2009

Copyright $\odot 2009$ Society for Neuroscience $\quad$ 0270-6474/09/290303-10\$15.00/0 retention/retrieval motifs have been identified. However, an arginine residue uniquely present in the channel pore region of the edited GluR-B subunit has been reported to regulate ER exit by preventing the transport of homomeric GluR-B receptors (Greger et al., 2002, 2003). Another mechanism, based on an extracellularly located splice form-specific valine/leucine residue, inhibits the ER exit of homomeric flop-type GluR-A and GluR-D AMPA receptors (Coleman et al., 2006).

Point mutations in the agonist-binding domain of Caenorhabditis elegans GLR-1 (Grunwald and Kaplan, 2003), mammalian kainate (Mah et al., 2005; Valluru et al., 2005; Fleck, 2006; Priel et al., 2006), and AMPA receptor subunits (Greger et al., 2006) have been reported to impede the expression of the cognate receptors on cell surface. The nature of the responsible mechanism(s) and the importance of agonist-binding activity itself, for the transport of AMPA receptors, are still poorly understood. Further, AMPA receptors are unique in their association with stargazin family regulatory proteins [transmembrane AMPA receptor regulatory proteins (TARPs)] (Chen et al., 2000; Tomita et al., 2003). We investigated the early trafficking of GluR-D AMPA receptors carrying mutations in the ligand-binding domain (LBD) to eliminate agonist binding or desensitization. Our results indicate that agonist-binding activity is essential for the transport of GluR-D to plasma membrane both in cell lines and in neurons, whereas the ability to desensitize may play a less critical role. Furthermore, we demonstrate that coexpression with stargazin is able to overcome the transport block of the 
nonbinding AMPA receptor mutants in cell lines. Our results are consistent with the hypothesis that both glutamate and stargazin make additive incremental contributions to structural stability of AMPA receptor ligand-binding domain and thereby promote the exit of the receptor from the endoplasmic reticulum.

\section{Materials and Methods}

DNA constructs. Plasmids for the expression of wild-type and mutated fulllength AMPA receptor subunits in mammalian cells were constructed in pcDNA3.1 (Stratagene). GluR-D flip $\left(\right.$ GluR- $\left.D_{i}\right)$ and flop $\left(G l u R-D_{o}\right)$ expression plasmids have been described previously (Pasternack et al., 2002; Coleman et al., 2006). GluR-D $D_{i}$ point mutations R507K, E727D, and E727Q were made by replacing the wild-type restriction fragment with the corresponding fragment in the respective mutant construct made originally in the insect cell vector pFastbacl (Jouppila et al., 2002). The L505Y mutation was introduced in pFastbacl by overlap extension PCR with mutagenic primers. All GluR- $\mathrm{D}_{\mathrm{i}}$ constructs, except for L505Y (untagged), contained a Flag epitope inserted between the signal peptide and the first residue of the predicted mature polypeptide (alanine-22). Wild-type and mutated GluR-D S1S2 fusion protein cDNAs (Lampinen et al., 1998, 2002) were transferred from pFastbacl as NheI-HindIII fragments into pEGFP-C1 (Clontech), replacing the green fluorescent protein (GFP) sequence as described previously (Coleman et al., 2006).

Antibodies. Primary antibodies used in immunofluorescence staining were monoclonal M1 anti-Flag (Sigma; $5 \mu \mathrm{g} / \mathrm{ml}$ ), and Fab7 and Fab22 (both at $10 \mu \mathrm{g} / \mathrm{ml}$ ) (Jespersen et al., 2000). Secondary antibody used was Cy3conjugated anti-mouse $(7 \mu \mathrm{g} / \mathrm{ml})$ from Jackson ImmunoResearch Labora-

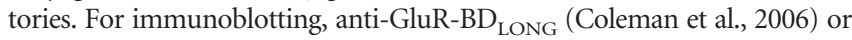
anti-stargazin (1:5000) made in-house were used. Commercial antibodies used were rabbit anti-myc (AbCam; $0.1 \mu \mathrm{g} / \mathrm{ml}$ ) and rabbit anti-NMDAR1 (Chemicon; $0.2 \mu \mathrm{g} / \mathrm{ml}$ ); secondary antibody used was anti-rabbit conjugated to horseradish peroxidase (Amersham Biosciences; 1:5000).

Cell culture and transfection. HEK293 and COS-7 cells were cultured and transfected as described previously (Coleman et al., 2003). For coexpression, cDNAs were transfected at a 1:1 ratio. For drug treatments, 50 $\mu \mathrm{M}$ 2,3-dihydroxy-6-nitro-7-sulfamoyl-benzo[f] quinoxaline-2,3-dione (NBQX) (Tocris) in DMSO or $100 \mu \mathrm{M}$ 1-(4-aminophenyl)-4-methyl7,8-methylenedioxy-5H-2,3-benzodiazepine hydrochloride (GYKI52466) (Tocris) in ethanol was added immediately after transfection; control cells received vehicle only. The cells were analyzed as described below. For patch clamp experiments, the cells were cotransfected with pEGFP-C1 for visualization of GFP fluorescence. Primary cortical neurons were isolated from embryonic day 18 mouse embryos and transfected after $10 \mathrm{~d}$ in vitro (d.i.v.) and analyzed at 14 d.i.v. as previously described (Cai et al., 2006).

Electrophysiology. Whole-cell patch clamp recordings were made from GFP-positive HEK293 cells with Axopatch 200B amplifier and Clampex 8.2 software (Molecular Devices) (Möykkynen et al., 2003). Electrodes were pulled from borosilicate glass capillaries (World Precision Instruments) and had a resistance of $4-6 \mathrm{M} \Omega$ when filled with internal solution containing (in mM): $N$-methyl-D-glucamine 100; $\mathrm{CH}_{3} \mathrm{SO}_{3} \mathrm{H}$ 100; $\mathrm{CsF} 40$; $\mathrm{MgCl}_{2}$ 10; HEPES 10; EGTA 5, pH 7.4. The cells were continuously perfused with recording solution containing (in $\mathrm{mM}$ ): $\mathrm{NaCl} 150 ; \mathrm{KCl} 2.5$; $\mathrm{CaCl}_{2}$ 2.5; $\mathrm{MgCl}_{2}$ 1; HEPES 10; glucose 10, $\mathrm{pH}$ 7.4. Glutamate was dissolved in the recording solution and the $\mathrm{pH}$ of the solution was adjusted to 7.4. Glutamate was applied to the cells using a stepper motor driven applicator (Warner Instrument). The recordings were digitized using a Digidata 1322A analog to digital converter (Molecular Devices) with a sampling rate of $10 \mathrm{kHz}$ and filtering using a lowpass bassel filter at $1 \mathrm{kHz}$. Each glutamate application was done twice and traces were averaged. Prism 4.0 software (GraphPad) was used for the statistical analysis.

Immunofluorescence analysis. Transfected COS-7 cells were fixed and immunostained $40 \mathrm{~h}$ after transfection, as previously described (Coleman et al., 2006). Neuronal staining was done as described (Cai et al., 2006). Images were obtained and analyzed as previously described (Cai et al., 2006; Coleman et al., 2006) with an Olympus Provis AX70 epifluorescence microscope coupled to a Photometrics SenSys air-cooled CCD camera and Image ProPlus software.
Cell surface biotinylation, protein secretion, and immunoblot quantification. Transfected HEK293 cells were biotinylated with EZ-Link SulfoNHS-SS-Biotin (Pierce) as described previously (Coleman et al., 2006). Triton X-100 extracts were bound to streptavidin-conjugated Sepharose (Amersham Biosciences), and precipitated proteins were harvested and analyzed as described earlier (Coleman et al., 2003). For analysis of GluR-D S1S2 construct secretion, growth media were collected from transfected HEK293 cells $40 \mathrm{~h}$ after transfection, and $1 \mathrm{~mm}$ PMSF was added. Cell debris was pelleted by centrifugation $\left(1500 \times g, 5 \mathrm{~min}, 4^{\circ} \mathrm{C}\right)$. Samples of media and total cell extracts prepared in Triton X-100 were analyzed by SDS-PAGE and immunoblotting (Coleman et al., 2003). Immunoblots were scanned via Adobe Photoshop and analyzed using Image ProPlus software as described (Coleman et al., 2006).

Endoglycosidase $H$ treatment. Triton X-100 extracts from transfected cells were incubated with Endoglycosidase H (New England Biolabs) according to manufacturer's instructions and as previously described (Coleman et al., 2006).

Statistical analysis. Statistical analyses of the electrophysiological and ligand-binding data were performed by using GraphPad Prism 4.02 (GraphPad Software). Numerical data are expressed as arithmetic mean \pm SEM, or as the mean with its $95 \%$ confidence interval in parentheses, as indicated.

\section{Results}

Ligand-binding domain mutations for transport studies

To study the role of agonist binding in cellular transport of AMPA receptors, we engineered mutations in the flip isoform of GluR-D (GluR-D $\mathrm{D}_{\mathrm{i}}$ ), which is efficiently expressed on the plasma membrane in transfected COS-7, HeLa, and HEK293 cells, whereas the flop isoform is retained in the ER (Coleman et al., 2006). We focused on two key residues directly involved in agonist binding, arginine-507 (R507) and glutamate-727 (E727) (Fig. 1). R507 is homologous to GluR-B (GluR2) R506, which interacts with the $\alpha$-carboxylate of glutamate and other agonists, whereas E727 (corresponding to GluR-B E726) has hydrogen bond and coulombic interaction with the $\alpha$-amino group of the agonist (Fig. $1 B$ ). Previous studies have demonstrated that even the relatively conservative R507K and E727Q mutations lead to a complete or near-complete loss of agonist-binding activity as determined by radioligand ( $\left.\left[{ }^{3} \mathrm{H}\right] \mathrm{AMPA}\right)$ binding assay or by fluorescence titration, whereas E727D mutation preserves binding, although with somewhat lowered affinity for glutamate (Lampinen et al., 1998; Abele et al., 2000; Jouppila et al., 2002). To analyze the role of desensitization, we used a leucine-to-tyrosine mutation (L505Y), which in other AMPA receptor subunits leads to loss of desensitization (Stern-Bach et al., 1998; Robert et al., 2001; Sun et al., 2002). This residue does not make any direct contacts with the agonist. Rather, it contributes to a subunit interface which is presumably characteristic of the short-lived active (non-desensitized) conformation and is stabilized by the tyrosine mutation (Sun et al., 2002). Consistent with this structural information, the L505Y mutation, introduced either in the fulllength GluR-D or in the S1S2 ligand-binding domain construct, did not significantly affect the agonist-binding properties in radioligand binding assay (supplemental Table 1, available at www.jneurosci.org as supplemental material).

To verify the functional status of the mutant receptors, wholecell patch clamp recordings were made from transfected HEK293 cells (Fig. 2). L-Glutamate (10 mM) elicited rapidly desensitizing currents in both wild-type (wt) and E727D receptor channels (Fig. 2A), whereas no responses could be recorded for R507K and E727Q mutants in agreement with their inactivity in agonist binding (Jouppila et al., 2002). Glutamate responses showed similar rates of desensitization for wild-type and E727D channels; time constant for dissociation, $\tau_{\mathrm{des}}$, was $5.1 \pm 0.30 \mathrm{~ms}(n=16)$ 


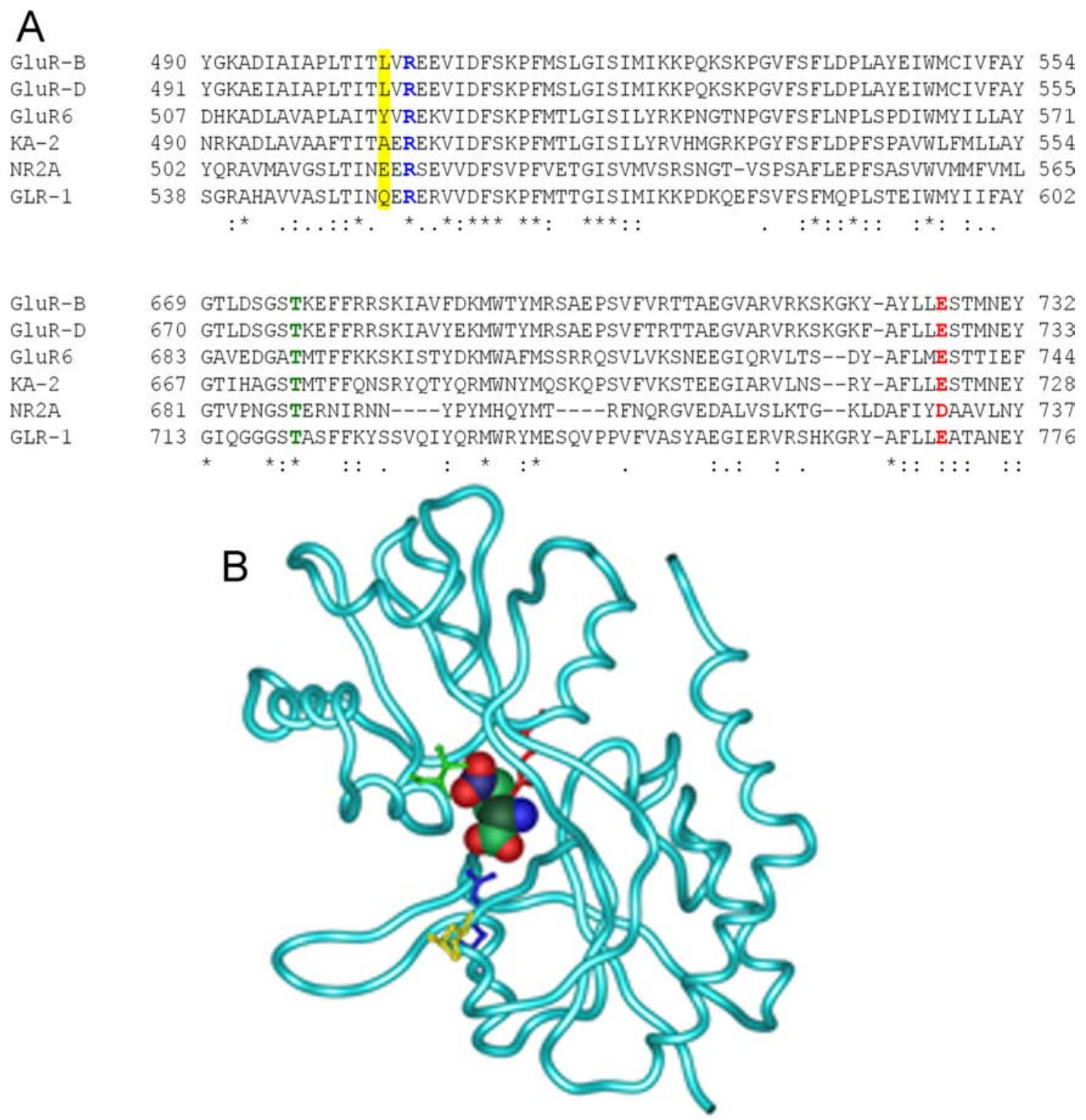

Figure 1. Location of the mutated residues. A, Sequence alignment indicating the positions of the residues corresponding to GluR-D L505Y (yellow), R507 (blue), T677 (green), and E727 (red) in AMPA receptor subunit GluR-B, kainate receptor subunits GluR6 and KA-2, NMDA receptor subunit NR2A, and Caenorhabditis elegans GLR-1. Sequence numbering starts from first methionine, thus including the signal peptide. B, Model of GluR-B S1S2 in complex with glutamate (1FTJ) (Armstrong and Gouaux, 2000) showing the residues equivalent to GluR-D residues L505, R507, T677, and E727. Color codes are as before. Bound glutamate is shown as van der Waals spheres. The figure was prepared by using iMol (courtesy of P. Rotkiewicz, Burnham Institute for Medical Research, La Jolla, (A).

for wt GluR-D $\mathrm{D}_{\mathrm{i}}$ and $5.8 \pm 0.36 \mathrm{~ms}(n=9)$ for E727D. A substantial non-desensitizing steady state current was observed with the E727D mutant but not with wt GluR-D (Fig. 2A). Glutamate triggered a robust non-desensitizing current in GluR-D L505Y channels (Fig. 2A), in agreement with earlier findings in other AMPA receptor subunits (Stern-Bach et al., 1998; Robert et al., 2001, Sun et al., 2002; Mitchell and Fleck, 2007). Responses to AMPA $(100 \mu \mathrm{M})$ were qualitatively similar to those obtained with glutamate, except that L505Y channels showed an initial desensitizing component in addition to the sustained nondesensitizing current (supplemental Fig. 1, available at www. jneurosci.org as supplemental material). Dose-response analysis revealed that L505Y and E727D mutations exert strong but opposite effects on glutamate potency: the former produced a 40 fold increase, whereas the E727D channels showed a 32-fold decrease in potency (Fig. $2 \mathrm{~B}$ ). The corresponding $\mathrm{EC}_{50}$ values were
49 (47-52) $\mu \mathrm{M}, 2.0$ (1.6-2.5) mM, and 64 (41-98) mM for L505Y, wild-type, and E727D GluR-D $D_{i}$ channels, respectively. The leftward shift in the glutamate dose-response curve of L505Y is consistent with reported effects of analogous mutations in other subunits (Stern-Bach et al., 1998; Robert et al., 2001; Mitchell and Fleck, 2007). In contrast to glutamate, AMPA potencies were not strongly affected by the mutations: $\mathrm{EC}_{50}$ values were 86 (81-91) $\mu \mathrm{M}$ for wt GluR-D, 100 (95-105) $\mu \mathrm{M}$ for E727D, and 30 (24-38) $\mu \mathrm{M}$ for L505Y mutant (Fig. $2 B$ ).

\section{Elimination of agonist binding prevents trafficking of GluR- $D$ to cell surface}

We analyzed the cellular localization of GluR- $D_{i}$ mutants in transfected COS-7 cells by immunofluorescence microscopy. Comparison of anti-Flag immunostaining in permeabilized and nonpermeabilized cells indicated that while all constructs had 
closely similar overall expression levels, the nonbinding R507K and E727Q mutant receptors were largely absent from cell surface, whereas wt GluR- $D_{i}$ and the E727D mutant showed intense surface staining (Fig. 3A). Because the Flag epitope was not present in the GluR-D $\mathrm{D}_{\mathrm{i}}$ L505Y construct, we used the monoclonal antibody Fab7 (Jespersen et al., 2000) for staining. This antibody is specific for a common N-terminal epitope in GluR-B and -D subunits. L505Y receptors were expressed in COS-7 cells as indicated by robust staining in permeabilized cells, but in contrast to bright Fab7 surface labeling of wt GluR- $\mathrm{D}_{i}$, only minimal L505Y staining was detected on the plasma membrane (supplemental Fig. 2, available at www.jneurosci.org as supplemental material) (Fig. 3A). We noticed that cultures transfected for expression of L505Y channels frequently contained floating/dead cells, prompting us to consider the possibility that moderate expression of the non-desensitizing GluR- $D_{i}$ L505Y channels may be toxic for the cells. The previously described electrophysiology results could result from low levels of channel expression, as detected by a more sensitive technique. Therefore, a similar immunostaining was performed for cells transfected and maintained in the continuous presence of NBQX, a competitive antagonist. Consistent with the predicted toxicity of L505Y expression, inclusion of $\operatorname{NBQX}(50 \mu \mathrm{M})$ in the culture medium led to a dramatic increase in the surface expression of L505Y, albeit not to wt GluR-D $\mathrm{D}_{\mathrm{i}}$ levels (Fig. $3 C$ ). In contrast, NBQX did not improve plasma membrane expression of the nonbinding R507K or E727Q mutants, nor did it have any effect on wt GluR-D $\mathrm{i}_{\mathrm{i}}$ or GluR-D , or E727D (Fig. $3 B$ ) (supplemental Figs. 3, 4, available at www.jneurosci.org as supplemental material). Furthermore, GYKI-52466 (100 $\mu \mathrm{M})$, a noncompetitive AMPA receptor antagonist, increased the surface expression of L505Y but not of the R507K mutant, similarly to what was observed with NBQX (supplemental Fig. 4, available at www.jneurosci.org as supplemental material).

To quantify the relative levels of cell surface expression of mutated GluR-D receptors, we used membrane impermeant biotinylation of transfected HEK293 cells (in the absence of NBQX). GluR- $D_{i}$ and the point-mutated receptors were expressed at similar levels as indicated by immunoblots probed with anti-BD $\mathrm{B}_{\mathrm{LONG}}$, which recognizes the cytoplasmic $\mathrm{C}$ terminus of GluR-D (Coleman et al., 2006) (Fig. 4A, C). In good agreement with fluorescence microscopy, only wt GluR-D $\mathrm{D}_{\mathrm{i}}$ and the E727D mutant were labeled with biotin (Fig. 4A,B). Plasma membrane levels of the GluR-D $\mathrm{D}_{\mathrm{i}}$ mutants R507K, L505Y, and E727Q were low and in the same range as those of the wild-type flop isoform, retained in the ER in transfected cell lines (Fig. 4A,B) (Coleman et al., 2006). Next, we determined the sensitivity of GluR- $D_{i}$ mutants to endoglycosidase $\mathrm{H}(\mathrm{EndoH})$ to identify the step in the secretory pathway affected by ligand-binding domain mutations. Of the four mutant receptors, only E727D showed resistance to EndoH as indicated by the separation of the broad receptor band into a doublet in SDS-PAGE (Fig. 4D). The extent of EndoHresistance of GluR-D $\mathrm{D}_{\mathrm{i}}$ E727D $(\sim 50 \%)$ was similar to that previ- ously observed for wt GluR-D $\mathrm{D}_{\mathrm{i}}$ (Coleman et al., 2006). In contrast, E727Q, R507K, and L505Y mutants were fully sensitive to EndoH treatment suggesting that the receptor mutants unable to reach the cell surface are primarily retained in the ER.

\section{LBD mutations block transport independently of the transmembrane and cytoplasmic domains of GluR-D} To find out whether the transport effects exerted by LBD mutations were entirely dependent on the native-like tetrameric structure or whether they could also manifest independently, by the LBD itself, we analyzed the secretion of S1S2 LBD constructs. In addition to the mutations tested in the full-length receptor, we included two further mutants, E727A and T677A; neither had activity in $\left[{ }^{3} \mathrm{H}\right] \mathrm{AMPA}$ binding assay (Lampinen et al., 1998, 2002). In GluR-B, the equivalent threonine residue to T677 forms essential interactions with the $\gamma$-carboxylate of glutamate (Armstrong and Gouaux, 2000). Immunoblot analysis of media and cell extracts of transfected HEK293 cells revealed that wt GluR- $D_{i}$ S1S2 and the E727D mutant were efficiently secreted into the culture medium, and the L505Y mutant showed an intermediate level of secretion, whereas all nonbinding mutant proteins were retained in the cells (Fig. 5A,B). These findings correlate well with those obtained with the full-length receptor constructs, including the contrasting behaviors of the flip and flop isoforms (Fig. 5) (Coleman et al., 2006), and strongly suggest that binding of an endogenous agonist (glutamate) to the LBD is obligatory for trafficking of GluR- $D_{i}$ forward from the ER. In addition, the results indicate that the integrity of the LBD can be monitored by cellular quality control independently of the assembled multimeric structure. 

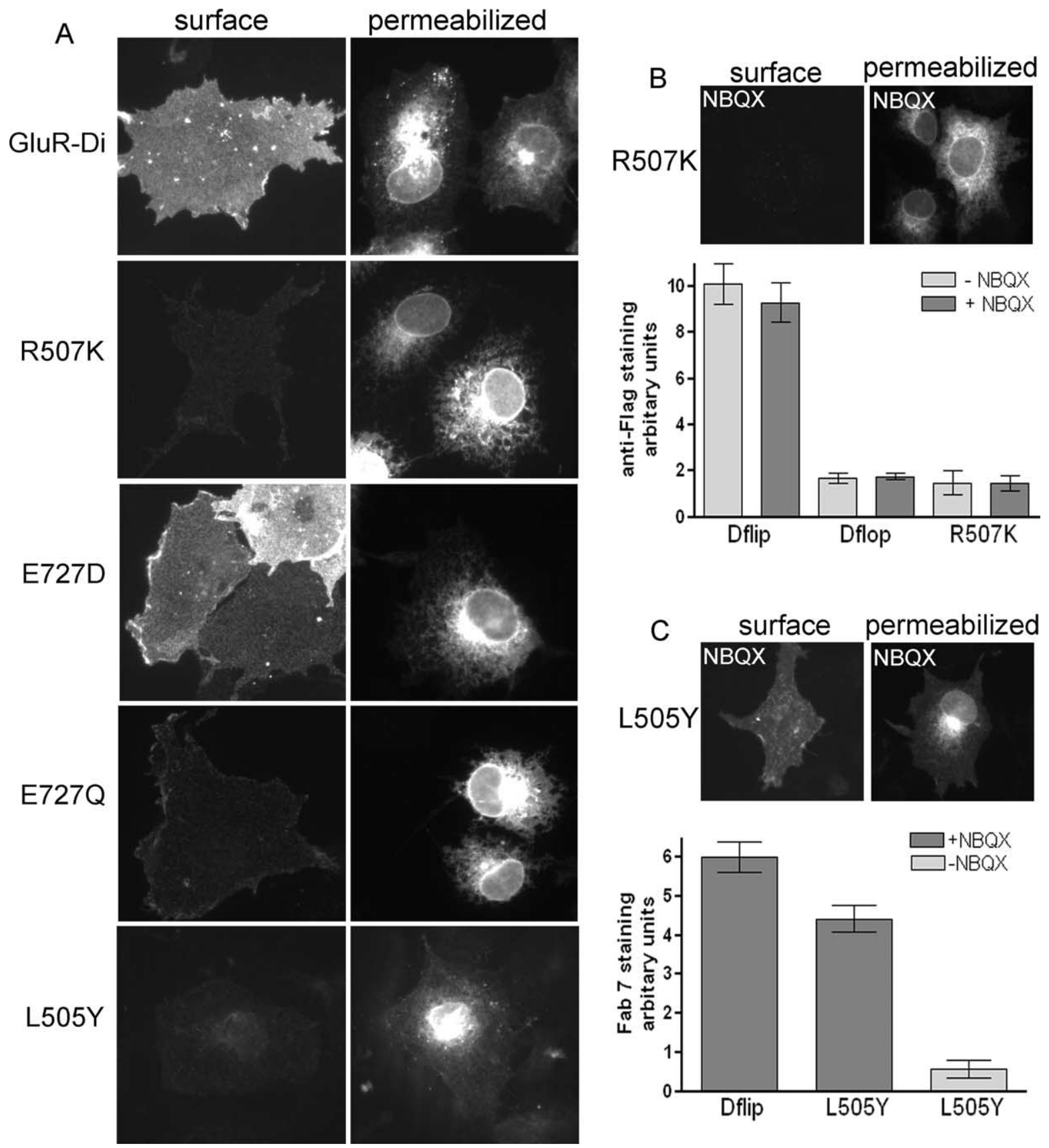

Figure 3. Immunofluoresence staining of point-mutated GluR-D receptors expressed in transfected COS-7 cells. The labeling was performed under nonpermeabilized conditions to reveal the surface staining, whereas the permeabilized staining indicates the total expression. Anti-Flag was used for all constructs except for L505Y, which lacks the Flag epitope, and was stained with monoclonal antibody Fab7 [see supplemental Fig. 2 (available at www.jneurosci.org as supplemental material) for additional controls]. $A$, No surface expression is observed in cells expressing nonbinding GluR-D $D_{i}$ mutants R507K and E727Q or for the non-desensitizing mutant L505Y. B, C, Inclusion of NBQX, a high-affinity competitive antagonist, has no effect on GluR-D $D_{i}$ R507K (B) but rescues the surface expression of GluR-D $D_{i} L 505 Y(C)$. Graphs show quantification of antibody surface labeling of cells expressing indicated constructs in the presence and absence of NBQX from the time of transfection.

Transport defect of GluR-D LBD mutants is rescued by stargazin coexpression

In neurons and in cell lines, transport of AMPA receptors from ER to cell surface is strongly promoted by stargazin and other TARPs (Chen et al., 2000; Vandenberghe et al., 2005a). Stargazin increases the surface expression of a non-desensitizing GluR-A mutant (L497Y) in oocytes but does not effect the surface expression level of the constitutively active Lurcher-like mutant (Tomita et al., 2007), indicating that the underlying molecular interactions are dependent on specific receptor conformations. Because the effects of binding site mutations have not previously been analyzed, it was of interest to examine whether the trafficking of GluR- $D_{i}$ mutants would be influenced by the presence of stargazin. Unexpectedly, all GluR- $\mathrm{D}_{\mathrm{i}}$ mutant receptors, including the nonbinding R507K and E727Q receptors, became readily detectable by cell surface biotinylation when coexpressed with stargazin (Fig. 6A, top panel). Densitometric analysis of the blots indicated similar overall expression levels and steady-state surface levels for all constructs (Fig. $6 B, C$ ), although the surface expression of L505Y and E727D mutants showed more variation than others, and, respectively, appeared 
somewhat lower and higher than the wildtype level (Fig. 6B). The differences had no statistical significance, however. These results demonstrate that stargazin is able to interact with and promote the trafficking of AMPA receptor mutants incapable of agonist binding.

Interestingly, stargazin changed the electrophoretic banding pattern of the mutant receptors. In the absence of stargazin, both wild-type and mutated receptors migrated as a single major band (Fig. $4 \mathrm{~A}$, bottom panel), whereas in the presence of stargazin, all GluR-D constructs except for wt GluR-D $\mathrm{D}_{\mathrm{i}}$ resolved as clear doublets (Fig. $6 A$, middle panel). This is suggestive of a less stringent coupling between glycan processing and passage through the secretory pathway for GluR- $\mathrm{D}_{\mathrm{i}}$ in the presence of stargazin. To ascertain whether stargazin expression could cause a general relaxation of ER quality control, we examined the transport to cell surface of GluR$\mathrm{D}_{\mathrm{i}} \Delta 22-162$, a deletion mutant not transported to the cell surface, most probably caused by incomplete folding in the absence of a substantial N-terminal polypeptide fragment (Pasternack et al., 2002). As an additional control, we used the NRla subunit of the NMDA receptor, which is poorly expressed on the cell surface when expressed without NR2A or 2B subunits (McIlhinney et al.,1998; Okabe et al., 1999). As determined by biotinylation assay, GluR-D $D_{i} \Delta 22-162$ and NR1a showed a minimal presence on the plasma membrane in transfected HEK293 cells both in the absence and in the presence of stargazin (supplemental Fig. $5 A, B$, available at www.jneurosci.org as supplemental material). Thus, stargazin does not induce a general, nonspecific relaxation in quality control of the secretory pathway. Furthermore, the ineffectiveness of stargazin with GluR-D $D_{i} \Delta 22-162$, a mutant receptor likely to have a gross folding defect, is consistent with the notion that stargazin interacts only with nearly or completely folded/assembled AMPA receptors (Vandenberghe et al., 2005b).

\section{LBD mutations prevent transport of GluR-D to cell surface in cultured cortical neurons}

The heterologous expression studies discussed above were performed in cell lines (COS-7, HEK293) that are well characterized model systems suitable for the analysis of general features and mechanisms of protein folding and transport; however, they do not natively express GluR-D or other AMPA receptor subunits. Therefore, it was important to complement the investigation with studies in neuronal cells that do endogenously express GluR-D on cell surface. For this purpose, we used cultured mouse cortical neurons. Immunofluorescence labeling with GluR-D N terminus-specific monoclonal antibody Fab22 (Jespersen et al., 2000) showed a punctate pattern of surface staining which became gradually more pronounced as the cultures approached maturity (supplemental Fig. 6, available at www.jneurosci.org as supplemental material).

To examine the role of agonist-binding activity in neuronal receptor transport, the cortical neurons were cotransfected with GFP and GluR-D cDNAs at 10 d.i.v. and visualized for GFP expression and anti-Flag surface staining at 14 d.i.v., a time when the endogenous GluR-D is well expressed. Clear and intense surface labeling was seen for recombinant GluR- $D_{i}$ and GluR-Do receptors, demonstrating that the block in the ER exit observed for GluR- $D_{0}$ in cell lines is not present in cortical neurons. In contrast, the nonbinding GluR- $\mathrm{D}_{\mathrm{i}}$ mutants R507K and E727Q, which also displayed a transport block in cell lines (in the absence of stargazin), did not show any surface expression in transfected neurons (Fig. 7). Because cortical neurons express stargazin and related TARPs (Tomita et al., 2003), the specific trafficking defect observed for the nonbinding GluR-D mutants implies differences in the quality control mechanisms and trafficking checkpoints between neurons and heterologous cells. 


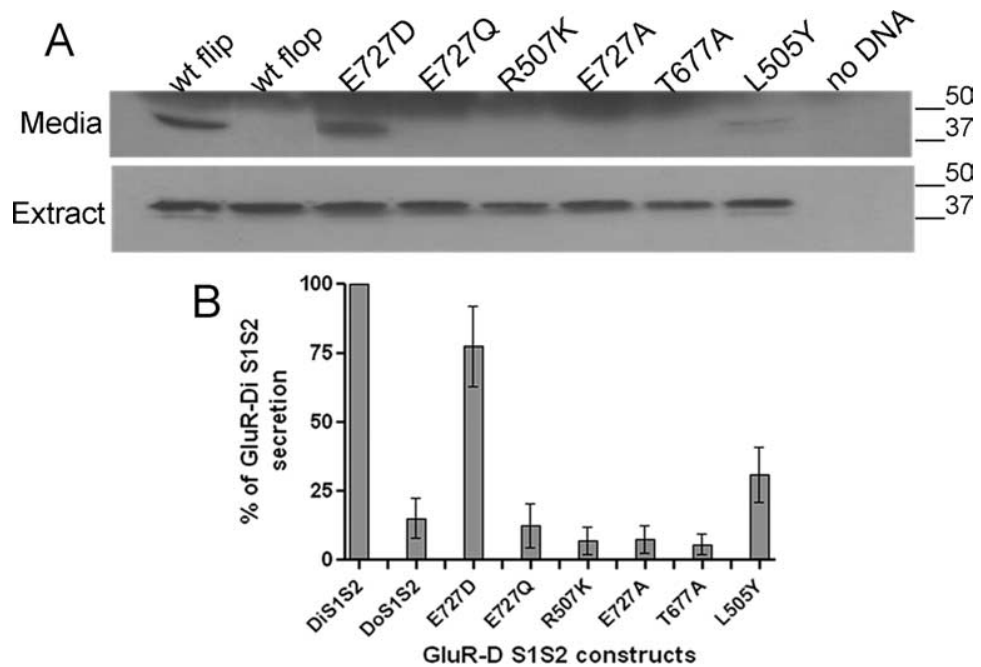

Figure 5. Secretion of GluR-D S1S2 ligand-binding domain constructs from transfected HEK293 cells. A, Anti-Myc immunoblots of HEK293 growth media $(\boldsymbol{A})$ and Triton X-100 extracts $(\boldsymbol{B})$ of cells collected $40 \mathrm{~h}$ after transfection. $\boldsymbol{B}$, Quantification of the immunoblots. Ratios of secreted and cell-associated immunoreactivities are shown in relation to wt GluR-D $D_{i} S 1 S 2$, given an arbitrary value of $100 \%$. The values and error bars correspond to a minimum of three independent experiments.
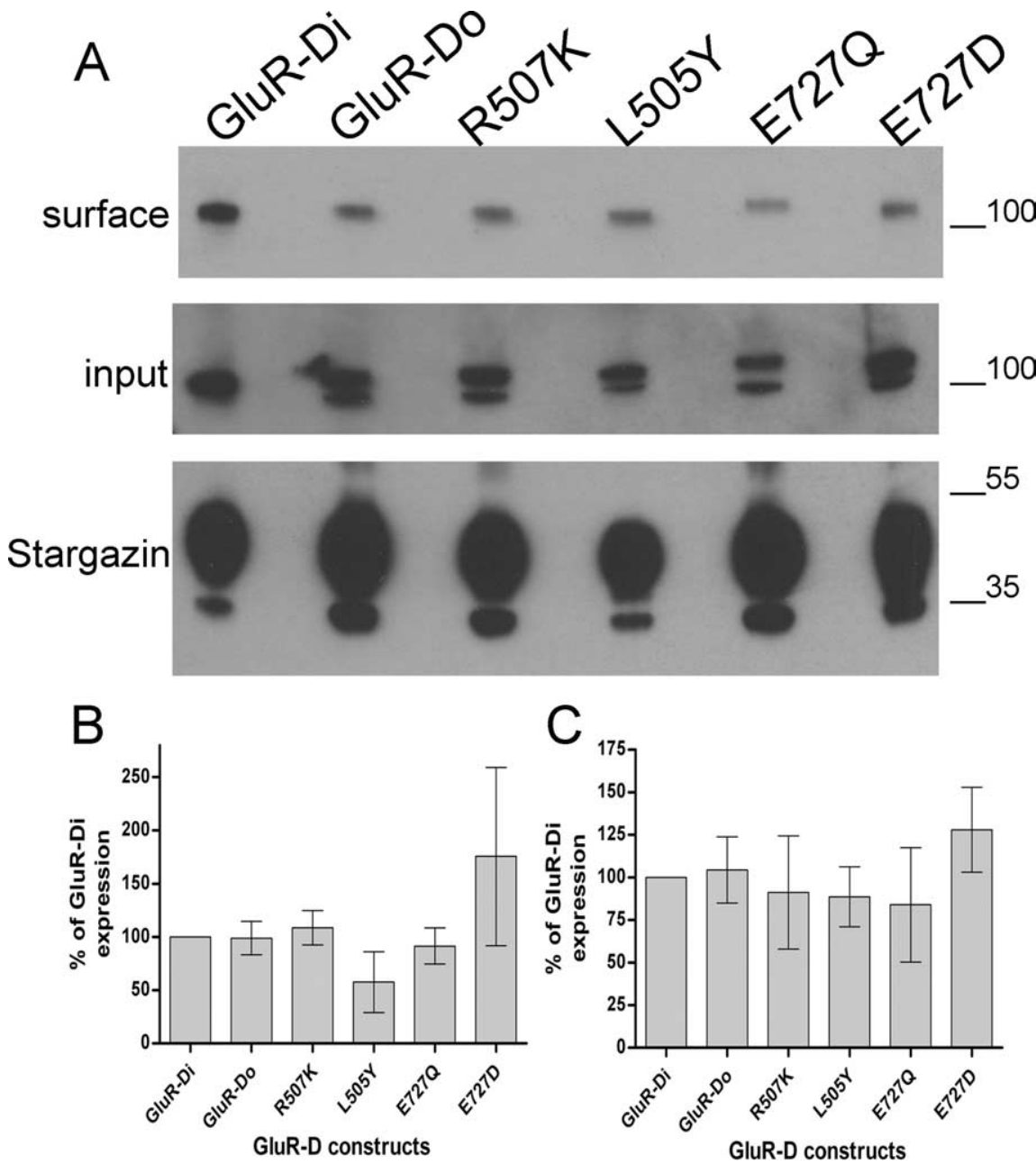

Figure 6. Coexpression with stargazin rescues the surface expression of GluR- $D_{i}$ mutants in HEK293 cells. $\boldsymbol{A}$, Biotinylation assay indicating levels of surface-expressed and total GluR- $D_{i}$ mutants and total stargazin levels as detected by immunoblotting with anti-BD ${ }_{\perp O N G}$ serum (top and middle) and with anti-stargazin serum (bottom). $B, C$, Quantification of surface $(\boldsymbol{B})$ and total $(\boldsymbol{C})$ GluR-D protein expression in HEK293 cells relative to wt GluR- $D_{\mathrm{i} .}$ Error bars indicate mean $\pm S D$, $n=4$. For controls in the absence of stargazin, see Figure $4 A-C$, representative of an experiment performed in parallel and under identical conditions.

\section{Discussion}

Our findings demonstrate that agonistbinding ability is indispensable for GluR-D AMPA receptor maturation and further suggest that glutamate-induced closure of the binding site cleft is registered by ER quality control as a necessary priming step for transport competence. In discussion of the underlying mechanisms, we will initially focus on agonist binding, as the sole crucial step, followed by consideration of the role of agonist-induced conformational shifts.

In its nascent state, the receptor is likely to have a relatively unstable structure with local unfolding favoring retention in the ER through recurrent interactions with luminal and transmembrane chaperones. It is conceivable that binding of endogenous glutamate and subsequent closure of the binding site cleft would provide structural stabilization, which may in itself push the receptor on to the forward pathway. Such a mechanism has been proposed for the effects of "pharmacological chaperones" on G-protein-coupled receptor trafficking (Morello et al., 2000; Petäjä-Repo et al., 2002). Calorimetric and spectroscopic studies actually indicate that glutamate binding confers substantial stability to GluR-D ligand-binding domain: Thermal denaturation point $\left(\mathrm{T}_{\mathrm{m}}\right)$ of GluR-D S1S2 protein is $+35-38^{\circ} \mathrm{C}$ in the absence and $+49^{\circ} \mathrm{C}$ in the presence of a saturating concentration of glutamate (Madden et al., 2000; Pasternack et al., 2003). Although corresponding data for the full-length GluR-D or other AMPA receptor subunits are not available, it is intriguing that these $\mathrm{T}_{\mathrm{m}}$ values suggest that under physiological conditions, association with glutamate would confer substantial stability to the otherwise metastable AMPA receptors. Independent support comes from the findings that nonbinding AMPA receptor mutants are fully transport competent when expressed in insect cells, which are cultured at $+27-28^{\circ} \mathrm{C}$, well below the $\mathrm{T}_{\mathrm{m}}$ of S1S2: GluR-D S1S2 mutants R507K and E727Q are efficiently secreted to culture medium (Lampinen et al., 1998), and fulllength GluR-A(R481K) mutant, corresponding to $\mathrm{R} 507 \mathrm{~K}$, is expressed on the cell surface at wild-type level (Kawamoto et al., 1997).

Next, we consider the role of additional glutamate-driven conformational shifts typical of AMPA receptor activity cycle (for review, see Mayer, 2006; Greger et al., 2007). A pore-loop mutation (Q608R) that eliminates homomeric channel activity has no effect on GluR-D surface expres- 
sion (Coleman et al., 2006), excluding the requirement for ion channel activity in forward trafficking, consistent with observations on other AMPA receptor subunits (Fleck, 2006). However, activity-related conformational transitions, in particular, desensitization, may still be essential for ER exit. The non-desensitizing GluR-B mutant (L504Y) has a poor surface expression in neurons, whereas a mutation (N768D) that accelerates desensitization has the opposite effect (Greger et al., 2006, 2007). Desensitization also seems important in kainate receptor trafficking, as mutant GluR6 receptors locked in a nondesensitizing conformation are poorly transported to cell surface (Priel et al., 2006). Consistent with these studies, we found that the non-desensitizing GluR- $D_{i}$ mutant L505Y does indeed have impaired cell surface expression. However, this was largely corrected by inclusion of an antagonist (NBQX or GYKI-54266) in the cultures. Obviously, the non-desensitizing, $\mathrm{Ca}^{2+}$-conductive mutant channels are toxic; much like heterologously expressed NR1a/NR2A NMDA receptors (Cik et al., 1993). Changes in membrane properties and/or loss of dying cells by shedding in the medium would readily account for the difficulties in visualizing L505Y transfectants in the absence of antagonist. However, some findings do suggest that additional factors, unique to the structural features of the mutant protein, may account for a minor part of the transport defect. First, the antagonist treatments did not completely rescue the surface expression of L505Y, suggestive of a remaining inherent defect. Second, L505Y S1S2 protein was secreted to the culture medium at a lower level than the other agonist-binding constructs (wt, E727D). Possibly, the highly stable dimer interface conferred by the leucine-to-tyrosine mutation, also present in the mutant S1S2 (Sun et al., 2002), interferes with the normal folding and maturation process. Therefore, consistent with what has been suggested for other AMPA and kainate receptors (Priel et al., 2006; Greger et al., 2007), the ability to desensitize may be involved in the maturation/early trafficking of GluR-D as well, but for

GluR-D, the role of desensitization is clearly of minor importance relative to agonist binding itself.

An implicit assumption of the above-discussed scenarios is that physiological glutamate concentrations in the ER are high enough to cause a significant occupancy of AMPA receptors. Unfortunately, the actual glutamate levels are not known, but glutamate is present in the ER and other compartments of the secretory pathway in amounts detectable by immunochemical staining (Meeker et al., 1989). Based on studies with synthetic

$E 727 Q$

GluR-Do anti-Flag.
GFP
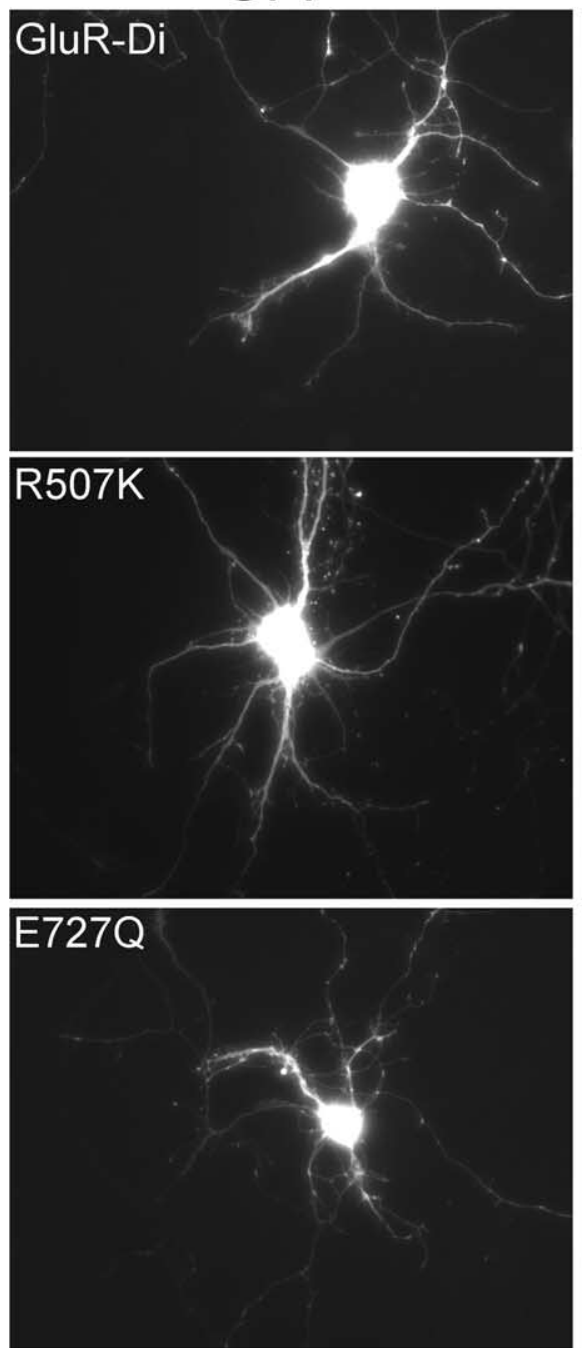

Figure 7. Expression of GluR- $D_{i}$, GluR- $D_{0}$, and GluR- $D_{i}$ mutants R507K and E727Q in mouse cortical neuronal cultures. Trans fected neurons were identified by GFP fluorescence. Surface expression was examined by labeling nonpermeabilized cells with
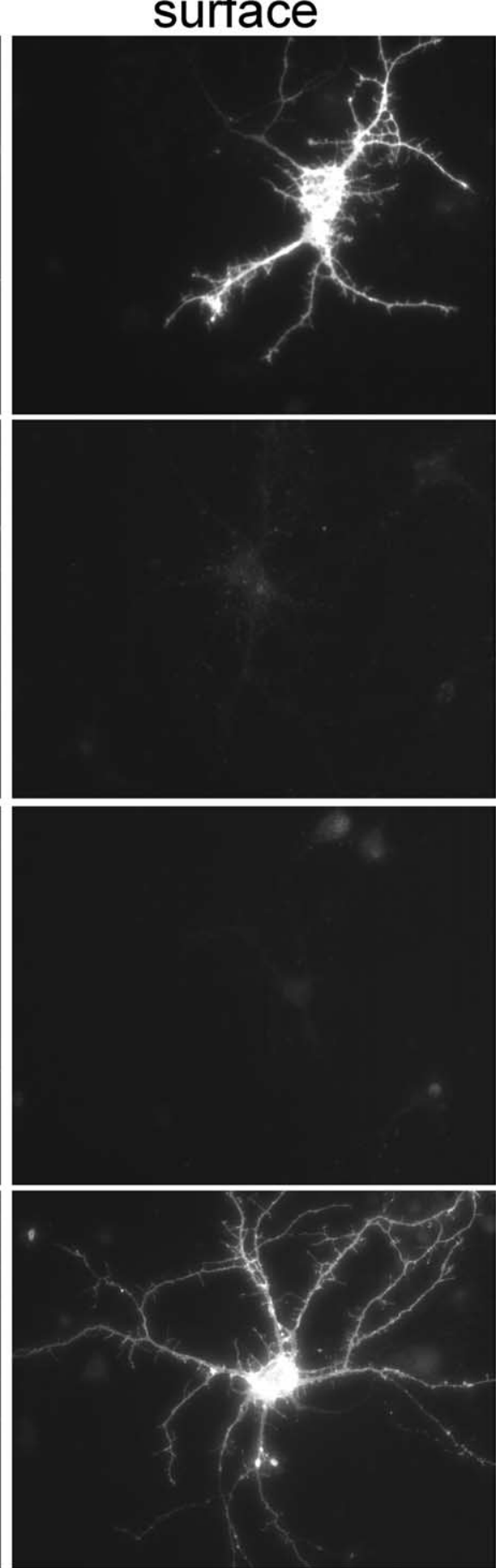

model compounds, the ER membrane, unlike most other cellular membranes, is permeable to small molecules (Le Gall et al., 2004). If this applies to glutamate, with cytosolic concentrations in the range of 1-10 mM (Ishikawa et al., 2002), AMPA receptors would be well saturated by agonist from early on in

their biosynthetic route, even if luminal glutamate concentrations were at somewhat lower levels.

The finding that coexpression with stargazin completely rescued the surface expression of nonbinding GluR- $\mathrm{D}_{\mathrm{i}}$ mutants in 
cell lines has implications for understanding stargazin-AMPA receptor interaction in the ER. The role of agonist binding in stargazin-AMPA receptor interaction is poorly understood; prolonged exposure to glutamate dissociates the stargazin-AMPA receptor complex (Tomita et al., 2004), although this may depend on the preparation (Vandenberghe et al., 2005b). Studies with chimeric TARPs imply extensive extracellular, transmembrane, and cytoplasmic interactions with AMPA receptors (Tomita et al., 2004), but the actual AMPA receptor regions contacted by stargazin have not yet been fully defined. The present findings indicate that stargazin can interact with and promote AMPA receptor trafficking in the absence of bound agonist. This suggests that contacts with the closed binding cleft or with the short-lived subunit interface, typical of the active nondesensitized conformation, have a more minor role than other interaction sites. The latter may include the linker regions between the ligand-binding domain and the transmembrane domains (Milstein and Nicoll, 2008); electron microscopy studies of AMPA receptors purified from native tissue show a transmembrane or juxtamembrane location for the majority of TARPassigned electron density (Nakagawa et al., 2005).

It is enlightening to relate our findings to the potential mechanisms underlying stargazin's chaperone-like activity on AMPA receptors. Stargazin may directly participate in subunit assembly, mask ER retention signals still present in the tetrameric channels and/or improve the structural stability of the receptor. Lack of association of stargazin with monomeric and dimeric subunit species in cerebellar extracts and the lack of excess, nonassembled subunits in stargazer mutant mice argue against a major role in the assembly, and suggest that stargazin associates exclusively with tetrameric receptors (Vandenberghe et al., 2005b). It is difficult to distinguish between the two remaining mechanisms mentioned above, especially as features typical of local unfolding are likely to serve as ER retention signals. For example, the complete rescue by stargazin of the ER transport block of GluR- $\mathrm{D}_{\mathrm{o}}$, assigned to amino acid 780 (Coleman et al., 2006), is consistent with both mechanisms, masking a flop-specific retention signal (Leu780) or alternatively, providing additional stability for ER exit. However, the well trafficked GluR- $\mathrm{D}_{\mathrm{i}}$ isoform lacks any obvious retention signals. Therefore, the dramatic increase in the surface expression of the nonbinding GluR- $\mathrm{D}_{\mathrm{i}}$ mutants in the presence of stargazin is best explained by an ability to increase the structural stability of the receptor, in an agonist-independent manner. In fact, because of its firm association with AMPA receptors, stargazin has been termed an auxiliary AMPA receptor subunit (Fukata et al., 2005; Vandenberghe et al., 2005b), a situation consistent with a mutually stabilizing relationship between the molecules. Furthermore, the induction of unfolded protein response in cerebellar granule cells of stargazer mice suggests that stargazin suppresses local unfolding of AMPA receptors, in agreement with a role in stabilizing AMPA receptor structure in the ER (Vandenberghe et al., 2005a).

In contrast to cell lines cotransfected with stargazin, the inactive binding site mutants R507K and E727Q were not expressed on the surface of transfected cortical neurons, indicating that endogenous TARP expression is not sufficient to overcome the transport block caused by the absence of bound glutamate. This finding emphasizes the crucial role of agonist binding for the transport of AMPA receptors to neuronal plasma membrane. Whether the apparent discrepancy between the neuronal and cell line transfectants is attributable to differences in concentrations of ER folding machinery components, insufficient levels of en- dogenous TARP, or the existence of additional neuron-specific quality control checkpoints, is unclear.

In conclusion, our findings invoke the hypothesis that AMPA receptors are synthesized as intrinsically unstable molecules, which require bound glutamate for structural stability and transport-competence. Thus, glutamate, binding early in the biogenesis, may be regarded either as a small-molecule chaperone or as a structural part of the intracellular AMPA receptor complex, to be disposed of by dissociation as the receptor reaches the cell surface. Additional stability may be provided by stargazin (and other TARPs) as part of the native complex. Considering the close structural similarity and related findings with other iGluR (Grunwald and Kaplan, 2003; Mah et al., 2005; Valluru et al., 2005), the requirement for agonist binding may be a general property of iGluR maturation.

\section{References}

Abele R, Keinanen K, Madden DR (2000) Agonist-induced isomerization in a glutamate receptor ligand-binding domain. A kinetic and mutagenetic analysis. J Biol Chem 275:21355-21363.

Armstrong N, Gouaux E (2000) Mechanisms for activation and antagonism of an AMPA-sensitive glutamate receptor: crystal structures of the GluR2 ligand binding core. Neuron 28:165-181.

Cai C, Li H, Rivera C, Keinänen K (2006) Interaction between SAP97 and PSD-95, two maguk proteins involved in synaptic trafficking of AMPA receptors. J Biol Chem 281:4267-4273.

Chen L, Chetkovich DM, Petralia RS, Sweeney NT, Kawasaki Y, Wenthold RJ, Bredt DS, Nicoll RA (2000) Stargazin regulates synaptic targeting of AMPA receptors by two distinct mechanisms. Nature 408:936-943.

Cik M, Chazot PL, Stephenson FA (1993) Optimal expression of cloned NMDAR1/NMDAR2A heteromeric glutamate receptors: a biochemical characterization. Biochem J 296:877-883.

Coleman SK, Cai C, Mottershead DG, Haapalahti JP, Keinänen K (2003) Surface expression of GluR-D AMPA receptor is dependent on an interaction between its C-terminal domain and a 4.1 protein. J Neurosci 23:798-806.

Coleman SK, Möykkynen T, Cai C, von Ossowski L, Kuismanen E, Korpi ER, Keinänen K (2006) Isoform-specific early trafficking of AMPA receptor flip and flop variants. J Neurosci 26:11220-11229.

Ellgaard L, Helenius A (2003) Quality control in the endoplasmic reticulum. Nat Rev Mol Cell Biol 4:181-191.

Fleck MW (2006) Glutamate receptors and endoplasmic reticulum quality control: looking beneath the surface. Neuroscientist 12:232-244.

Fukata Y, Tzingounis AV, Trinidad JC, Fukata M, Burlingame AL, Nicoll RA, Bredt DS (2005) Molecular constituents of neuronal AMPA receptors. J Cell Biol 169:399-404.

Greger IH, Khatri L, Ziff EB (2002) RNA editing at arg607 controls AMPA receptor exit from the endoplasmic reticulum. Neuron 34:759-772.

Greger IH, Khatri L, Kong X, Ziff EB (2003) AMPA receptor tetramerization is mediated by $\mathrm{Q} / \mathrm{R}$ editing. Neuron 40:763-774.

Greger IH, Akamine P, Khatri L, Ziff EB (2006) Developmentally regulated, combinatorial RNA processing modulates AMPA receptor biogenesis. Neuron 51:85-97.

Greger IH, Ziff EB, Penn AC (2007) Molecular determinants of AMPA receptor subunit assembly. Trends Neurosci 30:407-416.

Grunwald ME, Kaplan JM (2003) Mutations in the ligand-binding and pore domains control exit of glutamate receptors from the endoplasmic reticulum in C. elegans. Neuropharmacology 45:768-776.

Ishikawa T, Sahara Y, Takahashi T (2002) A single package of transmitter does not saturate postsynaptic glutamate receptors. Neuron 34:613-621.

Jespersen LK, Kuusinen A, Orellana A, Keinänen K, Engberg J (2000) Use of proteoliposomes to generate phage antibodies against native AMPA receptor. Eur J Biochem 267:1382-1389.

Jouppila A, Pentikäinen OT, Settimo L, Nyrönen T, Haapalahti JP, Lampinen M, Mottershead DG, Johnson MS, Keinänen K (2002) Determinants of antagonist binding at the alpha-amino-3-hydroxy-5-methyl-4isoxazolepropionic acid receptor subunit, GluR-D. Role of the conserved arginine 507 and glutamate 727 residues. Eur J Biochem 269:6261-6270.

Kawamoto S, Uchino S, Xin KQ, Hattori S, Hamajima K, Fukushima J, Mishina M, Okuda K (1997) Arginine-481 mutation abolishes ligand- 
binding of the AMPA-selective glutamate receptor channel alpha1subunit. Brain Res Mol Brain Res 47:339-344.

Lampinen M, Pentikäinen O, Johnson MS, Keinänen K (1998) AMPA receptors and bacterial periplasmic amino acid-binding proteins share the ionic mechanism of ligand recognition. EMBO J 17:4704-4711.

Lampinen M, Settimo L, Pentikainen OT, Jouppila A, Mottershead DG, Johnson MS, Keinanen K (2002) Discrimination between agonists and antagonists by the alpha-amino-3-hydroxy-5-methyl-4-isoxazole propionic acid-selective glutamate receptor. A mutation analysis of the ligandbinding domain of GluR-D subunit. J Biol Chem 277:41940-41947.

Le Gall S, Neuhof A, Rapoport T (2004) The endoplasmic reticulum membrane is permeable to small molecules. Mol Biol Cell 15:447-455.

Mah SJ, Cornell E, Mitchell NA, Fleck MW (2005) Glutamate receptor trafficking: endoplasmic reticulum quality control involves ligand binding and receptor function. J Neurosci 25:2215-2225.

Madden DR, Abele R, Andersson A, Keinänen K (2000) Large-scale expression and thermodynamic characterization of a glutamate receptor agonist-binding domain. Eur J Biochem 267:4281-4289.

Mayer ML (2006) Glutamate receptors at atomic resolution. Nature 440:456-462

McIlhinney RA, Le Bourdelles B, Molnár E, Tricaud N, Streit P, Whiting PJ (1998) Assembly intracellular targeting and cell surface expression of the human N-methyl-D-aspartate receptor subunits NR1a and NR2A in transfected cells. Neuropharmacology 37:1355-1367.

Meeker RB, Swanson DJ, Hayward JN (1989) Light and electron microscopic localization of glutamate immunoreactivity in the supraoptic nucleus of the rat hypothalamus. Neuroscience 33:157-167.

Michelsen K, Yuan H, Schwappach B (2005) Hide and run. Arginine-based endoplasmic-reticulum-sorting motifs in the assembly of heteromultimeric membrane proteins. EMBO Rep 6:717-722.

Milstein AD, Nicoll RA (2008) Regulation of AMPA receptor gating and pharmacology by TARP auxiliary subunits. Trends Pharmacol Sci 29:333-339.

Mitchell NA, Fleck MW (2007) Targeting AMPA receptor gating processes with allosteric modulators and mutations. Biophys J 92:2392-2402.

Morello JP, Salahpour A, Laperrière A, Bernier V, Arthus MF, Lonergan M, Petäjä-Repo U, Angers S, Morin D, Bichet DG, Bouvier M (2000) Pharmacological chaperones rescue cell-surface expression and function of misfolded V2 vasopressin receptor mutants. J Clin Invest 105:887-895.

Möykkynen T, Korpi ER, Lovinger DM (2003) Ethanol inhibits alphaamino-3-hydyroxy-5-methyl-4-isoxazolepropionic acid (AMPA) receptor function in central nervous system neurons by stabilizing desensitization. J Pharmacol Exp Ther 306:546-555.

Nakagawa T, Cheng Y, Ramm E, Sheng M, Walz T (2005) Structure and different conformational states of native AMPA receptor complexes. Nature 433:545-549.

Nasu-Nishimura Y, Hurtado D, Braud S, Tang TT, Isaac JT, Roche KW (2006) Identification of an endoplasmic reticulum-retention motif in an intracellular loop of the kainate receptor subunit KA2. J Neurosci 26:7014-7021.

Okabe S, Miwa A, Okado H (1999) Alternative splicing of the C-terminal domain regulates cell surface expression of the NMDA receptor NR1 subunit. J Neurosci 19:7781-7792.

Pasternack A, Coleman SK, Jouppila A, Mottershead DG, Lindfors M, Pasternack M, Keinänen K (2002) Alpha-amino-3-hydroxy-5-methyl-4- isoxazolepropionic acid (AMPA) receptor channels lacking the N-terminal domain. J Biol Chem 277:49662-49667.

Pasternack A, Coleman SK, Féthière J, Madden DR, LeCaer JP, Rossier J, Pasternack M, Keinänen K (2003) Characterization of the functional role of the N-glycans in the AMPA receptor ligand binding domain. J Neurochem 84:1184-1192.

Petäjä-Repo UE, Hogue M, Bhalla S, Laperrière A, Morello JP, Bouvier M (2002) Ligands act as pharmacological chaperones and increase the efficiency of delta opioid receptor maturation. EMBO J 21:1628-1637.

Priel A, Selak S, Lerma J, Stern-Bach Y (2006) Block of kainate receptor desensitization uncovers a key trafficking checkpoint. Neuron 52:1037-1046.

Ren Z, Riley NJ, Garcia EP, Sanders JM, Swanson GT, Marshall J (2003a) Multiple trafficking signals regulate kainate receptor KA2 subunit surface expression. J Neurosci 23:6608-6616.

Ren Z, Riley NJ, Needleman LA, Sanders JM, Swanson GT, Marshall J (2003b) Cell surface expression of GluR5 kainate receptors is regulated by an endoplasmic reticulum retention signal. J Biol Chem 278:52700-52709.

Robert A, Irizarry SN, Hughes TE, Howe JR (2001) Subunit interactions and AMPA receptor desensitization. J Neurosci 21:5574-5586.

Scott DB, Blanpied TA, Swanson GT, Zhang C, Ehlers MD (2001) An NMDA receptor ER retention signal regulated by phosphorylation and alternative splicing. J Neurosci 21:3063-3072.

Sitia R, Braakman I (2003) Quality control in the endoplasmic reticulum protein factory. Nature 426:891-894.

Standley S, Roche KW, McCallum J, Sans N, Wenthold RJ (2000) PDZ domain suppression of an ER retention signal in NMDA receptor NR1 splice variants. Neuron 28:887-898.

Stern-Bach Y, Russo S, Neuman M, Rosenmund C (1998) A point mutation in the glutamate binding site blocks desensitization of AMPA receptors. Neuron 21:907-918.

Sun Y, Olson R, Horning M, Armstrong N, Mayer M, Gouaux E (2002) Mechanism of glutamate receptor desensitization. Nature 417:245-253.

Tomita S, Chen L, Kawasaki Y, Petralia RS, Wenthold RJ, Nicoll RA, Bredt DS (2003) Functional studies and distribution define a family of transmembrane AMPA receptor regulatory proteins. J Cell Biol 161:805-816.

Tomita S, Fukata M, Nicoll RA, Bredt DS (2004) Dynamic interaction of stargazin-like TARPs with cycling AMPA receptors at synapses. Science 303:1508-1511.

Tomita S, Shenoy A, Fukata Y, Nicoll RA, Bredt DS (2007) Stargazin interacts functionally with the AMPA receptor glutamate-binding module. Neuropharmacology 52:87-91.

Valluru L, Xu J, Zhu Y, Yan S, Contractor A, Swanson GT (2005) Ligand binding is a critical requirement for plasma membrane expression of heteromeric kainate receptors. J Biol Chem 280:6085-6093.

Vandenberghe W, Bredt DS, (2004) Early events in glutamate receptor trafficking. Curr Opin Cell Biol 16:134-139.

Vandenberghe W, Nicoll RA, Bredt DS (2005a) Interaction with the unfolded protein response reveals a role for stargazin in biosynthetic AMPA receptor transport. J Neurosci 25:1095-1102.

Vandenberghe W, Nicoll RA, Bredt DS (2005b) Stargazin is an auxiliary AMPA receptor subunit. Proc Natl Acad Sci U S A 102:485-490.

Xia H, Hornby ZD, Malenka RC (2001) An ER retention signal explains differences in surface expression of NMDA and AMPA receptor subunits. Neuropharmacology 41:714-723. 